\title{
FIBER REINFORCED SAND BACKFILL FOR UNDERGROUND PEDESTRIAN CROSSING
}

\author{
Andrey B. Ponomarev*, V.I. Kleveko, O.V. Moiseeva, \\ K.R. KASHAPOVA \\ Perm National Research Polytechnic University, Kuibysheva street 109, Perm, Russia \\ * corresponding author: spstf@pstu.ru
}

ABstract. Crosswalk is an essential element of the transport system of any city. A priority assignment in any such crossing is to ensure the safety of pedestrians. Underground pedestrian crossings are much safer than crossings at another level, but they lose in attraction when it comes to cost. The cost of the construction of an underground pedestrian crossing often leads to project abandonment. The cost of construction can be reduced through the use of flexible corrugated metal structures instead of ordinary concrete structures. The stress-strain state of the structural shells need to be known to facilitate their rational design.

The stress-strain state of flexible corrugated metal shells largely depends on the strength and deformation characteristics of the surrounding soil. Therefore, improving the characteristics of backfill soil is an urgent task in reducing the cost of construction for such tunnels.

One way to improve the strength and deformation characteristics of soils is the use of reinforcement. Currently, there are a large number of reinforcement schemes and also associated reinforcing materials. One of the most prospective methods of soil reinforcement is the use of fibre filaments. Fibre reinforced soils have significantly higher strength and deformation characteristics in comparison with unreinforced soils.

Numerical modelling of a tunnel shell made out of a corrugated metal structure was undertaken to evaluate the effectiveness of using fibre reinforced sand. Ordinary sand and sand reinforced with polypropylene fibres have been used as soil backfill.

The calculation results for a pedestrian tunnel structure involving different strength and deformation characteristics of the backfill soil are presented in this article.

KEYwORDs: Fibre reinforced soil, FEM, tunnel lining.

\section{INTRODUCTION}

Crosswalk is an integral element of the transportation system of any city. The first and foremost function of a pedestrian crossing is user safety. Annually, in Russia, a large number of people travelling on foot are killed, which indicates some lack of effectiveness in the transfer and transport system as a whole [1, 2].

The most commonly used and the most projected type is a pedestrian crossing with a light regulation of type "Zebra". This type of transit actually maximises the probability of pedestrian-car contact.

Underground pedestrian crossings offer a significantly safer transit to light regulation, but lose on the cost criterion. This cost of construction often leads to abandonment of the concept. However, the cost of construction can be reduced through the use of corrugated metal structures instead of the standard concrete shell [3, 6].

To reduce the earthworks and consequently the cost of construction, the pedestrian tunnel is laid at the ground-level for traffic vehicles and in this case is carried out using the device of the mound (Fig. 11).

Earlier studies showed that the optimal cross section is a round pipe [6].
The stress-strain state of flexible metal corrugated shells largely depends on the strength and deformation characteristics of the surrounding soil [7, 8]. Therefore, the characteristics of the soil backfill gives an actual opportunity to reduce the cost of construction of pedestrian tunnels.

One way to improve the strength and deformation characteristics of soils is the use of reinforcement. Currently, there are a large number of schemes for reinforcement and their related reinforcing materials.

\section{FIBRE REINFORCED SANDY BACKFILL}

One of the most promising ways of reinforcement of soils is using fibre. Fibre reinforced soils have a significantly higher strength characteristics compared to unreinforced soils [9 12].

Fig. 1 shows the structure of the pedestrian crossing at ground level. This design of pedestrian crossing does not need light regulation, and thus saves time for drivers and pedestrians, requires less effort compared to aboveground and underground pedestrian crossings and generally serves to enhance the safety of all road users. 


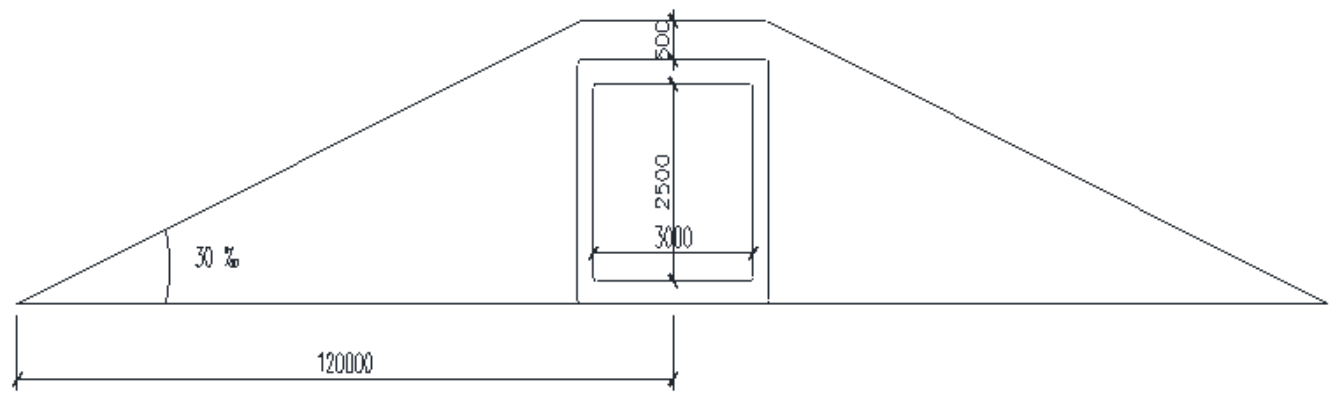

FigURE 1. The construction of a pedestrian crossing at ground level

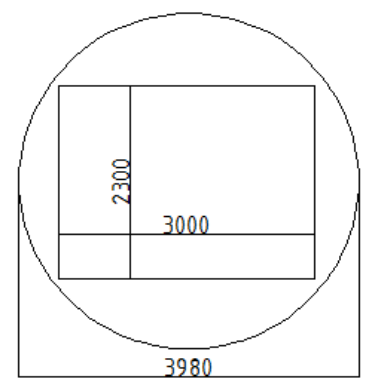

Figure 2. A round pipe

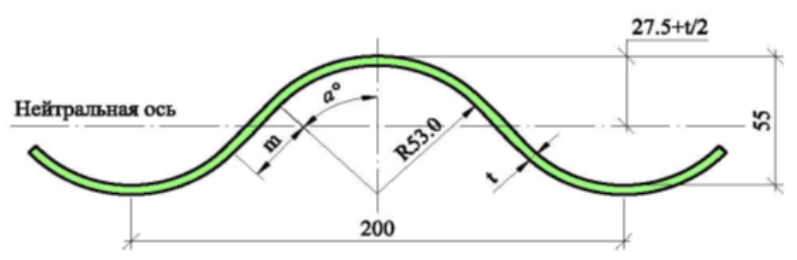

Figure 3. Specifications of corrugated sheet GL 55

To identify the optimal soil backfill there was calculation by the finite element method, implemented in the software package PLAXIS 2D.

The construction of a pedestrian crossing at ground level was made for specific geological conditions. At the construction site there were identified the following primers:

- loam, layer thickness $h=7.2 \mathrm{~m}$, intercept cohesion $c=20.5 \mathrm{kPa}$, angle of internal friction $\varphi=18^{\circ}$, modulus of deformation $E=11 \mathrm{MPa}$;

- sand, $h=1.0 \mathrm{~m}, c=2 \mathrm{kPa}, \varphi=18^{\circ}, E=11 \mathrm{MPa}$;

- gravel, $h=1.8 \mathrm{~m}, c=1 \mathrm{kPa}, \varphi=40^{\circ}, E=30$ $\mathrm{MPa}$;

- mudstone, $h=2.1 \mathrm{~m}, E=20 \mathrm{MPa}$.

Fig. 2 shows the geometrical dimensions of a metal corrugated pipe.

In the pipe there was used corrugated sheet GL55 (Fig. 3), which had the following characteristics:

- thickness - $4 \mathrm{~mm}$;

- the moment of inertia of the cross section $I$ $181.92 \mathrm{~cm}^{4} / \mathrm{m}$;

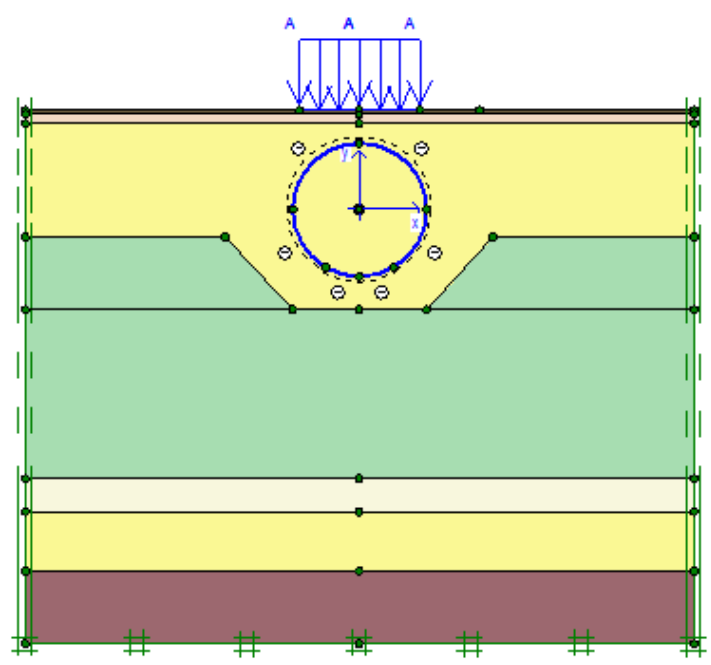

FiguRE 4. Design scheme

- the moment of resistance of section $W$ $61.67 \mathrm{~cm}^{3} / \mathrm{m}$;

- the plasticity moment of resistance of section $W_{p}$ $79.72 \mathrm{~cm}^{3} / \mathrm{m}$.

The most common soil backfill for underground structures is sand. Therefore, to evaluate the influence of soil characteristics on the stress-strain state of the shirred casing, two calculations were done. The first calculation was derived from a filling with sand with the following characteristics: $E=30 \mathrm{MPa} ; \varphi=40^{\circ}$; $C=1 \mathrm{kPa}$. The second calculation was made for the filling out of fibrocartilagenous sand with the following characteristics: $E=30 \mathrm{MPa} ; \varphi=45^{\circ}$; $C=67.0 \mathrm{kPa}$. The characteristics of sand reinforced with polypropylene fibres to an amount of $0.5 \%$ is taken from test results given in $9-12$.

According to the current design standard SP 35.13330.2011 "Bridges and pipes", the cargo load was a four-axle truck N14 with an axle load of $252(\mathrm{kN})$, and the distance between the axles $1.2 \mathrm{~m}$.

The design scheme is shown in Fig. 4. The results of calculating the stress-stain state of the tunnel lining with soil backfill are in Figs. 5, 6, 7, and 8.

Analysis of the graphs showed that in the tunnel lining there occurs compressive strength with a maximum value of $N_{\max }=147.87 \mathrm{kN}$ and a considerable alternating bending moment with a maximum value 


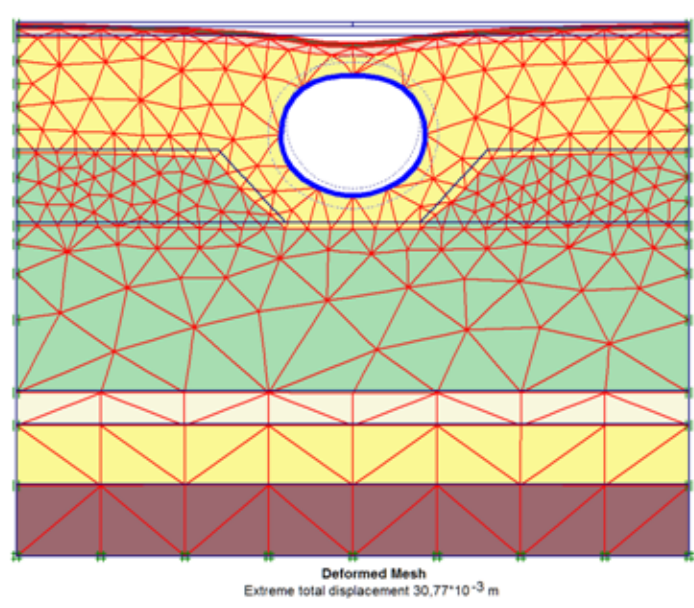

Figure 5. Deformed scheme

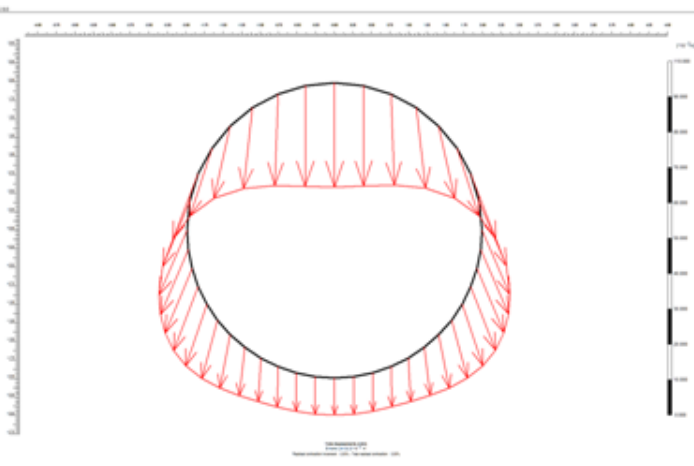

Figure 6. The diagram of shell displacements for sand backfill $\left(u_{\max }=29.32 \mathrm{~mm}\right)$

of $M_{\max }=6.5 \mathrm{kNm}$. The maximum displacement of the tunnel lining was observed in the upper zone and amounted to $29.32 \mathrm{~mm}$.

The results from calculating the stress-strain state of the tunnel lining and soil backfill from fibroareolar sand is shown in Figs. 9,10 and 11

Based on the calculation results the following data was obtained:

- $\max$. travel: $I_{\max }=20.71 \mathrm{~mm}$;

- $\max$ axial force $N_{\max }=164.28 \mathrm{kN}$;

- $\max$ bending moment $M_{\max }=3.78 \mathrm{kNm}$.

The analysis of the above plots shows that using fibre reinforced soil instead of unreinforced soil leads to a decrease of the deformations of the tunnel shell by $8.6 \%$, a bending moment at $42 \%$ and to an increase in longitudinal force of $9.7 \%$.

Based on the obtained calculation results there were calculated the normal stresses in the metal corrugated shell. The calculation results are presented in Figs. 12 and 13.

The analysis of these plots shows that the normal stresses in a metal enclosure when using the filling out fibre reinforced soil is much less than for soil that is unreinforced.

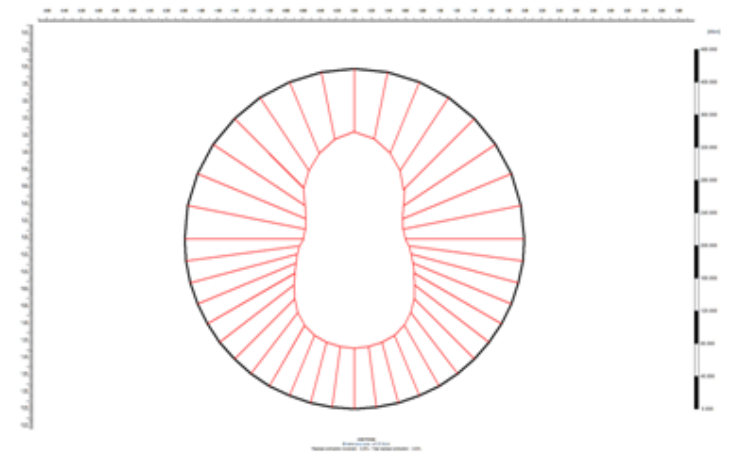

Figure 7 . The diagram of axial force for sand backfill $\left(N_{\max }=147.87 \mathrm{kN}\right)$

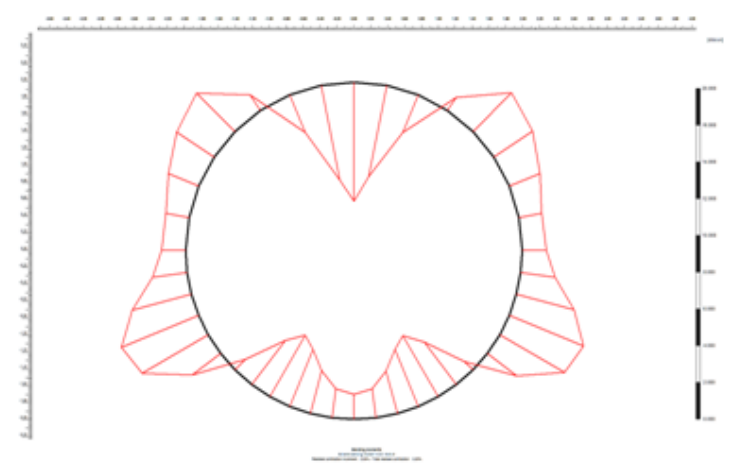

Figure 8. The diagram of bending moment for sand backfill $\left(M_{\max }=6.5 \mathrm{kNm}\right)$

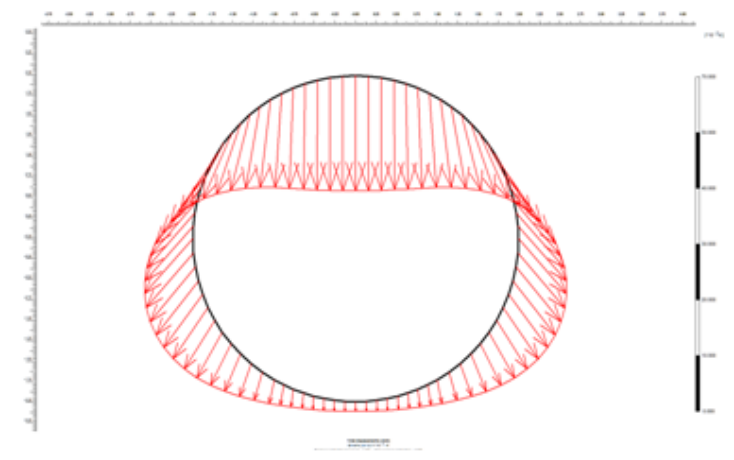

Figure 9. The diagram of shell displacements for fibre reinforced sand backfill $\left(u_{\max }=20.71 \mathrm{~mm}\right)$

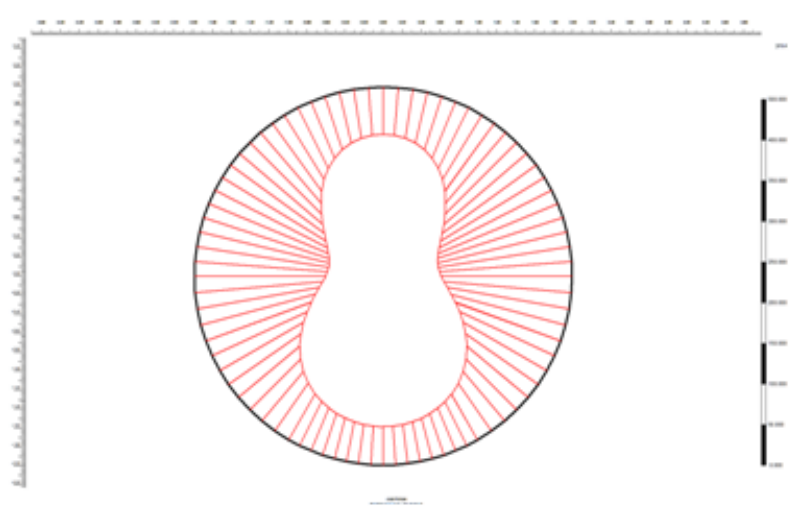

FiguRE 10. The diagram of axial force for fibre reinforced sand backfill $\left(N_{\max }=164.28 \mathrm{kN}\right)$ 


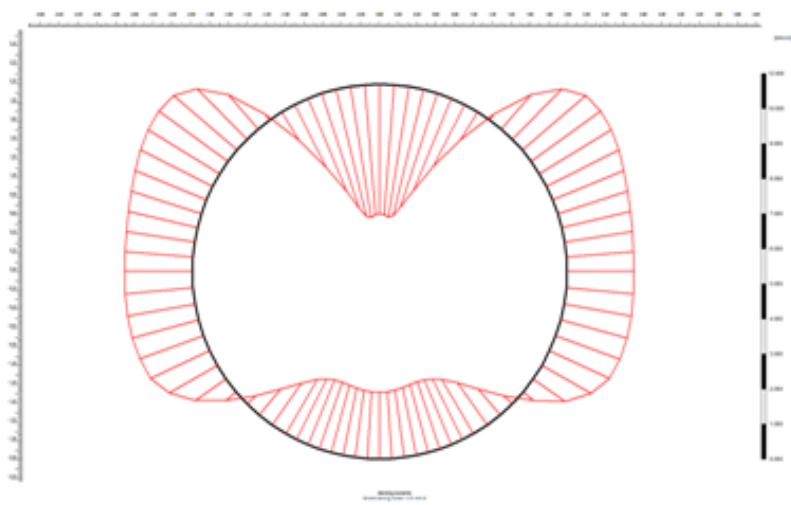

FiguRE 11. Bending moment diagram for fibre reinforced sand backfill $\left(M_{\max }=3.78 \mathrm{kNm}\right)$

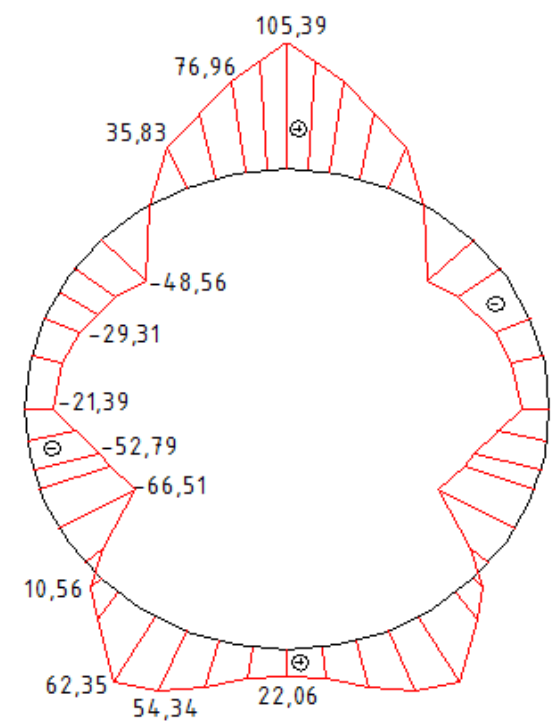

FiguRE 12. Stress diagram for sand backfill $\left(\sigma_{\max }=\right.$ 105.39 MPa)

\section{Conclusions}

(1.) Using fibre reinforced soil can improve the strength and deformation characteristics of the soil backfill corrugated metal tunnel lining, which leads to a significant reduction of stresses and strains in it. Stress was reduced by $42 \%$, and the deformation by $8.6 \%$.

(2.) The results of the calculations showed that improvement of the mechanical characteristics of the soil backfill for the tunnel allows the use of thinner corrugated sheets, which reduces the cost of construction.

\section{REFERENCES}

[1] O. Moiseeva, V. Kleveko. Analysis of accident cases involving pedestrians in perm. PNRPU Construction and Architecture Bulletin (4):134-143, 2015.

[2] P. A. Tretyakova, V. Kleveko. Modern methods of increasing the efficiency of urban transport systems. PNRPU Construction and Architecture Bulletin (1):101-108, 2012.

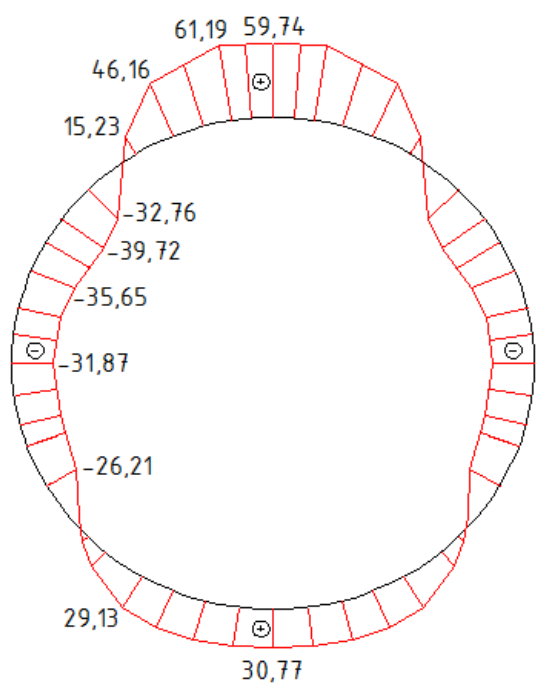

FiguRE 13. Stress diagram for fibre reinforced sand backfill $\left(\sigma_{\max }=61.19 \mathrm{MPa}\right)$

[3] O. V. Moiseeva, V. I. Kleveko. Choice of a rational type of pedestrian crossing with safety for pedestrians and construction costs. World Science and Innovation 8(2):90-93, 2015.

[4] A. E. Polovnikova, V. I. Kleveko. Choice of a rational type of pedestrian crossings with regard to the safety of pedestrian traffic. Modernization and research in the transport sector 2:356-361, 2015.

[5] O. V. Moiseeva, V. I. Kleveko. Choice of rational type of crosswalk with regard to the safety for pedestrians and the cost of construction. SWorldJournal J21504. (2(9)):3-5, 2015.

[6] O. V. Moiseeva, V. I. Kleveko. Using prefabricated corrugated metal structures for the construction of a pedestrian tunnel. Modern scientific researches and innovations 12(56):409-411, 2015.

[7] V. V. Kovalchuk. The effect of corrugated elements thickness on the deflected mode of corrugated metal structures. Nauka ta progres transportu 3(57):199-207, 2015 .

[8] A. L. Novodzinsky, V. I. Kleveko. The account influence of a thickness of the goffered element on durability and stability of a metal water throughput pipe. PNRPU Construction and Architecture Bulletin (1):81-94, 2012.

[9] V. I. Kleveko, Y. M. Shangina. The impact of the use of fibre reinforced sand as backfilling on the value of act. SWorldJournal 04(116 (10)):16-21, 2016.

[10] A. B. Ponomarev, A. S. Kuznetsova, V. G. Ofrikhter. Application of fibroreinforced sand as the foundation of buildings and constructions. Bulletin of Volgograd State University of Architecture and Civil Engineering Series: Construction and Architecture (30):101-107, 2013.

[11] A. S. Kuznetsova, V. G. Ofrikhter, A. Ponomarev. Strength research of sand reinforced by discrete polypropylene fibres. PNRPU Construction and Architecture Bulletin (1):44-55, 2012.

[12] A. B. Ponomarev, A. S. Kuznetsova. Laboratory testing of the strength characteristics of fibre reinforced sand with various water. Bulletin of Civil Engineers 6(47):127-132, 2014. 